\title{
A further patient with Pai syndrome with autosomal dominant inheritance?
}

Sabine Rudnik-Schöneborn, Klaus Zerres

\begin{abstract}
We report a patient with median cleft of the upper lip, cutaneous facial polyps, and lipoma of the corpus callosum who represents a further case of Pai syndrome. The father of the patient showed coloboma of the right iris and shared some facial dysmorphism with his son, thus raising the question of autosomal dominant inheritance.
\end{abstract}

\section{( $\mathcal{J}$ Med Genet 1994;31:497-498)}

Pai syndrome is a rare disorder consisting of the combination of median cleft upper lip and cutaneous polyps of the facial skin and nasal mucosa as obligate criteria. ${ }^{1-5}$ In addition, midline lipomas of the central nervous system are part of the syndrome, which have been detected in one patient only. ${ }^{4}$ This patient is the second who shares identical features with the patient described by Pai et al. ${ }^{4} \mathrm{His}$ family history may contribute further to the understanding of the underlying pathogenesis of Pai syndrome.

\section{Case report}

The proband was the first son of an unrelated couple born after an uneventful pregnancy (weight $3390 \mathrm{~g}$, length $51 \mathrm{~cm}$, head circumfer-

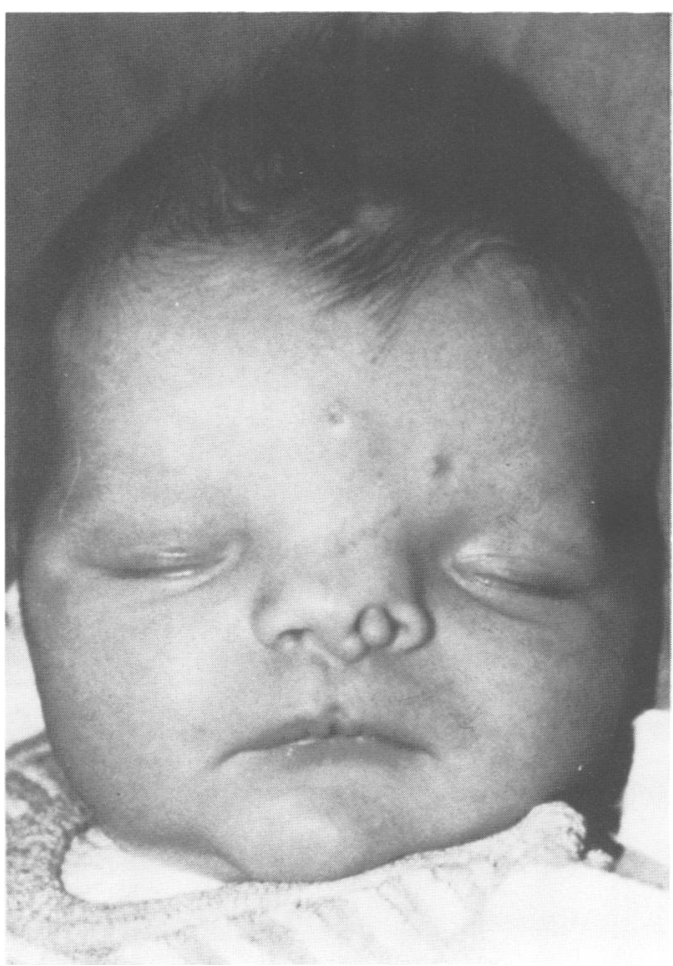

Figure 1 The child's face at 1 week of age showing the median cleft lip, nasal polyps, and skin tags. ence $36 \mathrm{~cm}$ ). At birth pedunculated cutaneous masses were noticed extending from the left nostril and the nasal bridge (fig 1). Additional skin tags containing cartilage tissue were seen on his broad forehead. His eyes were widely spaced with downward slanting palpebral fissures. Because of a median cleft lip and the facial dysmorphism, a malformation syndrome was suspected. Cranial ultrasound and a CT scan of the head showed a lipoma of the corpus callosum and an abnormal configuration of the third ventricle. The median cleft lip was associated with a bifid uvula and a high palate. Other investigations including chromosome analysis showed normal results.

The polyps were surgically removed at the age of 10 days and a follow up examination at the age of 1 year showed normal psychomotor development.

The 31 year old father showed some similarities in facial appearance to his son (fig 2),
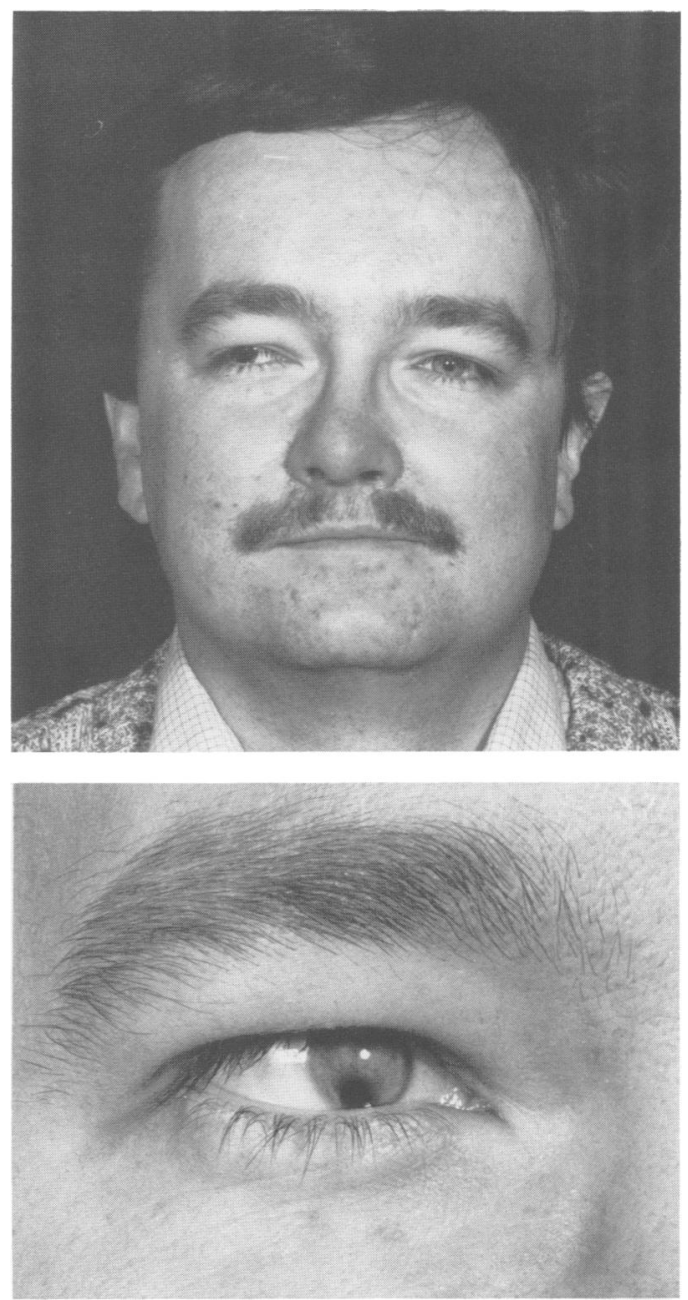

Figure 2 Facial appearance and coloboma of the right iris of the father at 31 years of age.
Revised version accepted for publication 1993
Institute for

Human Genetics, Wilhersity of Bonn, 53111 Bonn, Germany K Zerres

Correspondence to Dr Rudnik-Schöneborn. 
although neither a cleft lip nor skin polyps could be detected. He was seen in various children's hospitals in his first two years of life because he had complete coloboma of the right iris. Moreover, hydrocephalus was suspected because of his broad forehead and downward slanting palpebral fissures. His development was entirely normal. A CT scan at the age of 31 years showed an abnormally shaped right eyeball but was otherwise unremakable.

\section{Discussion}

The few reports of Pai syndrome have been exclusively sporadic cases, all male patients between a few months and 21 years of age, ${ }^{1-5}$ suggesting a non-genetic aetiology. The mother of the patient described by Pai et $a l^{4}$ had a similar facial appearance and clinodactyly. Since a CT scan showed enlarged lateral ventricles, a genetic aetiology was discussed.

Cleft lip is generally ascribed to insufficient mesenchymal proliferation at 6 weeks of embryonic development. ${ }^{67}$ Consequently the cutaneous polyps might be the result of an excess of mesodermal tissue in the oral cavity at the same embryonic stage. ${ }^{3}$ Interestingly, the formation of coloboma occurs at the same time of development (5 to 6 weeks) and is the result of disturbed mesodermal migration in the optic cup leading to a failure of closure of the choroid fissure. ${ }^{6}$ The origin of intracranial lipoma remains to be identified but this anomaly is most likely to occur later in cerebral development. It is not known yet whether lipomas are a major feature in Pai syndrome, since in three out of five cases no data are given on investigations of the brain. ${ }^{1-3}$

The prognosis of Pai syndrome after surgical repair is satisfactory and mental impairment is not a feature of the syndrome. The only patient with central nervous system lipoma ${ }^{4}$ was 7 years old when last examined and showed no abnormalities. (G S Pai, personal communication).

We conclude that a common genetic defect in mesodermal differentiation might be responsible for the combination of coloboma and Pai syndrome in the family described here.

1 Sharma LK. Median cleft of the upper lip. Plast Reconst Surg 1974;53:155-7.

2 Ponniah RD. Midline cleft lip with associated abnormalities. f Laryngol Otol 1977;91:177-8

3 Nakamura J, Tomonari $\mathrm{H}$, Goto S. True median cleft of the upper lip associated with three pedunculated club-shaped skin masses. Plast Reconstr Surg 1985;75:727-31.

4 Pai GS, Levkoff AH, Leithiser RE. Median cleft of the upper lip associated with lipomas of the central nervous system and cutaneous polyps. Am $\mathcal{F}$ Med Genet 1987;26:921-4.

Reardon W, Jones B, Baraitser M Median clefting of the upper lip associated with cutaneous polyps. $7 \mathrm{Med}$ Genet 1990;27:337-8.

6 O'Rahilly R, Müller F. Human embryology and teratology. New York: Wiley-Liss, 1992.

7 Beck F, Moffat DB, Davies DP. Human embryology. Oxford: Blackwell Scientific Publications, 1985. 